\title{
A Rede dos Gestores Locais em São Paulo*
}

\author{
Eduardo Cesar Leão Marques \\ Universidade de São Paulo (USP), São Paulo, SP, Brasil. E-mail: ecmarq@uol.com.br
}

\section{INTRODUÇÃO}

\begin{abstract}
$\mathrm{A}_{\mathrm{d}}^{\mathrm{c}}$ constituição das capacidades de governo envolve dimensões de natureza administrativa, técnica e financeira, a construção de apoio político. Mas também depende da existência de um amplo conjunto de gestores aptos a ocupar os cargos de comando nas mais variadas agências, potencialmente capazes de gerar coesão, coordenação e disseminação de informações no interior do Estado, e inserção em campos da sociedade civil, assim como de realizar articulação com outros níveis de governo. Até o momento, a literatura tem tratado o tema como associado à construção histórica do Estado brasileiro (Nunes, 1997; Abrucio, Pedroti e Pó, 2010; Gouvêa, 1994, por exemplo) e à formação de burocracias e coordenação de políticas (Abrucio, 2007; Loureiro e Abrucio, 1999; D’Araújo e Lameirão, 2011, entre outros) com a consequente formação de capacidades estatais (Pires e Gomide, 2014 e Bichir, 2014), assim como ligado à construção de maiorias em casas legislativas no âmbito de nosso presidencialismo de coalizão (Abranches, 1988; Amorim Neto, 1994; Vieira, 2013). Adicionalmente, são escassos os estudos em nível municipal (Couto, 1998; Praça e Garcia, 2011 e Garcia, 2013). Uma faceta não considerada do fenômeno
\end{abstract}

\footnotetext{
* Agradeço a Samuel Ralize, Betina Saruê e Gabriela Trindade que sistematizaram as informações aqui trabalhadas. Adicionalmente, Gabriela Trindade buscou informações biográficas. O presente artigo seria impossível sem o trabalho destes pesquisadores.
}

DADOS - Revista de Ciências Sociais, Rio de Janeiro, vol. 60, non2, 2017, pp. 437 a 472. 
diz respeito à constituição de um tecido relacional no Estado (internamente e entre níveis de governo, entre Executivo e Legislativo e para o mundo privado e associativo), que se constitui pela própria migração ao longo do tempo de indivíduos entre posições de comando e cargos de livre indicação em agências. Esse é o tema trabalhado pioneiramente por esse artigo, focando o governo municipal de São Paulo.

O trabalho parte da premissa analítica de que as pessoas se relacionam com outras ao coabitarem numa mesma agência em um dado momento do tempo. A migração de pessoas entre cargos em agências produz, portanto, uma teia entre organizações similar ao tecido relacional do mundo dos negócios estudado classicamente pela literatura de interlocking directorates (Mintz e Schwartz, 1981 e, para o caso brasileiro, Lazzarini, 2011). A estrutura e a composição desse tecido relacional geram importantes consequências para a coordenação de políticas, a disseminação de informações e a estabilidade na produção de políticas. Embora este artigo analise o governo do município de São Paulo e apenas conexões no poder público fortemente centradas no Executivo local, contribui para pensar o mesmo fenômeno em outros níveis de governo.

Estudo aqui a rede construída pela migração de ocupantes de cargos de alto escalão (principalmente do Poder Executivo) em secretarias e outros órgãos da prefeitura de São Paulo entre 1985 e $2012^{1}$. A rede foi (re)montada a partir das informações sobre a ocupação de cargos em várias agências pelos mesmos indivíduos em diversos governos, associando organizações, setores de políticas e governos entre si. O tecido relacional resultante representa, portanto, as agências em cada governo como pontos ou nós, e as pessoas que ocuparam cargos em mais de uma agência como vínculos entre elas. A pesquisa parte de um banco de dados inédito organizado no Centro de Estudos da Metrópole com os ocupantes de cargos em 34 secretarias nos quatro mais altos níveis hierárquicos ao longo do período estudado, incluindo 5.037 pessoas em 111 diferentes tipos de cargos. Vale adiantar que a grande maioria da rede não é composta pela ocupação de múltiplos cargos do topo da hierarquia pelos mesmos indivíduos, mas, ao contrário, é tecida principalmente pela migração de ocupantes de cargos mais baixos ao longo de suas trajetórias.

Várias perguntas da pesquisa orientam a investigação: será que existe uma rede de burocratas de alto escalão em nível local que associa ges- 
tões de matizes ideológicos e setores de políticas distintos? Em caso positivo, o que a estrutura - critérios de especialização ou de afinidade política (ideologia, setor, coalizões de governo similares, contiguidade temporal)? Há gestões, agências ou setores mais centrais, e o que explica as suas centralidades?

O artigo está organizado em três seções, além desta introdução e da conclusão. Na seção que se segue, discuto a literatura sobre burocracia e ocupação de cargos no Brasil. Embora inexistam trabalhos similares a este investigando as redes constituídas pela ocupação de cargos em diversos governos, os debates realizados na última década sobre construção de burocracias, formação de gabinetes e ocupação de cargos auxiliam a delimitação das questões a serem abordadas. A segunda apresenta o banco de dados utilizado e as principais decisões envolvidas com a sua construção. A terceira e última seção analisa a rede dos ocupantes de cargos, investigando as conexões entre governos, as ligações produzidas pela migração dos ocupantes dos cargos mais importantes, assim como a rede entre agências em cada governo construída pela migração de todos os ocupantes de cargos. O artigo explora de forma detalhada a estrutura dessa rede, analisando a presença de elementos políticos e técnicos associados à construção de vínculos entre agências.

\section{A LITERATURA RECENTE SOBRE BUROCRACIA NO BRASIL}

Os padrões de indicações para cargos de chefia no Poder Executivo têm sido objeto de investigação recente nas ciências sociais brasileiras, mas sempre explorando os atributos de cargos e seus ocupantes e não a dimensão relacional da questão, como será desenvolvido aqui. Além disso, a quase totalidade da produção se concentra no nível federal, o que cria dificuldades para a construção de pontes analíticas com o tema deste artigo, embora ajude a compor um quadro conceitual para analisá-lo. Podemos dizer que três grandes questões organizam a produção sobre o tema - a construção histórica do Estado brasileiro e suas agências, os elementos que explicam a ocupação de cargos (dimensões políticas e técnicas), e qual seria o lugar da ocupação de cargos na formação de governo, na construção de coalizões e de coordenação governativa.

Um primeiro conjunto de trabalhos se preocupou com a construção das burocracias e das carreiras de Estado no Brasil. Abrucio, Pedroti e

DADOS - Revista de Ciências Sociais, Rio de Janeiro, vol. 60, nº 2, 2017 
Pó (2010), por exemplo, realizam uma extensa análise histórica da formação da burocracia brasileira desde o Império, passando pela Primeira República, pelos grandes momentos de formação das burocracias no Estado brasileiro, com o modelo do Departamento Administrativo do Serviço Público (Dasp) a partir de 1938 e o decreto-lei 200/1967 no regime militar, até o período democrático recente. Gouvêa (1994) percorreu trajetória similar, mas concentrou sua atenção na construção das burocracias da área econômica no Brasil e na formação das suas capacidades de intervenção, dos anos 1930 até a Nova República. Também em registro histórico, Gomes (1994) discutiu a formação das novas elites burocráticas - especialmente engenheiros e economistas - nos momentos cruciais de formação do Estado brasileiro na primeira metade do século XX. Em registro similar, Nunes (1997) sustentou que a relação entre Estado e sociedade no Brasil construiu historicamente as gramáticas do clientelismo, corporativismo, insulamento burocrático e universalismo de procedimentos, imbricadas umas sobre as outras na construção das agências e do corpo do Estado. Em análise interessada nos modelos de desenvolvimento econômico perseguidos pelo país historicamente, Bresser-Pereira (2007) analisou as relações entre classes dirigentes, elites burocráticas e elites econômicas.

Uma segunda grande questão de pesquisa endereçou a ocupação de cargos no Poder Executivo e suas transformações recentes. As formas de ingresso no serviço público convergiram para regras de impessoalidade e mérito com a universalização do concurso público a partir da Constituição de 1988. Entretanto, o Estado brasileiro ainda é marcado por uma grande quantidade de cargos de livre provimento, em especial nos postos de decisão de agências públicas. Portanto, entender o que explica as nomeações de cargos de livre provimento - se critérios técnicos ou políticos -, continua sendo central. Nesta direção, Abrucio (2007) discutiu a trajetória da gestão pública desde a Nova República, com destaque para o projeto de Reforma do Estado no período Bresser e o primeiro governo de Luiz Inácio Lula da Silva. Caminhando na mesma direção, Guedes (2013) analisou os impactos da criação da Escola Nacional de Administração Pública (Enap) em 1988 e da carreira de gestor governamental sobre a estruturação recente do Estado brasileiro. Machado (2013) também discutiu a carreira de gestor, embora com menos otimismo sobre seus efeitos. Monteiro (2013), por fim, sustentou que essa inovação restringiu o espaço para a patronagem, mesmo que na prática a incorporação dos gestores tenha tido impacto menor do que o imaginado originalmente. 
Além da carreira de gestor público, as burocracias federais da área econômica foram as mais analisadas até o momento. Abrucio, Loureiro e Rosa (1998) e Loureiro e Abrucio (1999), por exemplo, investigaram o perfil do provimento de cargos de alto escalão no Ministério da Fazenda e mostraram que a burocracia no Estado brasileiro tem perfil bastante aberto, com grande trânsito entre agências, as quais variam, entretanto, em um contínuo que vai dos ministérios militares (mais fechados e com baixa migração), passando pelo Itamaraty e pelo Ministério da Fazenda, para chegar aos demais ministérios (mais abertos e com alta migração). Como veremos no caso de São Paulo, também é possível perceber áreas temáticas mais fechadas e outras mais abertas. Olivieri (2007), por fim, explorou os padrões de indicação, mas introduziu elementos relacionais às motivações técnicas e política nas nomeações dos diretores do Banco Central.

Em um registro mais geral, Cruz (2009) analisou as mudanças no funcionalismo federal recente, demonstrando sinais de profissionalização, com expansão de concursos, criação do núcleo estratégico de carreiras do Estado e certa equalização salarial. Com relação aos cargos comissionados, entretanto, a autora indica avanço tímido de formas de controle, mas uma maior oferta de burocratas disputando tais vagas. D'Araújo e Lameirão (2011) analisaram a trajetória dos cargos de alto escalão (DAS 6 e 5) no governo Lula, investigando a quantidade, formação/especialização e remuneração de seus ocupantes. As autoras concluem que mesmo que haja indicações políticas, as qualificações dos ocupantes são condizentes com as funções. O estudo destaca ainda o engajamento social e político prévio dos ocupantes dos cargos, o que pode ter efeitos tanto positivos (inserção) para as políticas, quanto negativos (cooptação) para suas organizações civis de origem. Vieira (2013), por seu turno, analisou o papel das indicações no controle dos ministérios pelo presidente, em diferentes condições de coalizão. Essa linha de análise é complementada pelo estudo de Lopez (2015) sobre a ocupação de cargos no governo federal e seus principais condicionantes, buscando entender as escolhas dos ocupantes de cargos e a sua contribuição para a governabilidade e a coordenação governativa. Praça, Freitas e Hoepers (2012) analisam os tempos de permanência de cargos comissionados no governo federal, demonstrando que mudanças partidárias não influenciam nas mudanças de cargos, mas que estas se concentram mais na formulação de políticas do que na sua implementação (mais dependentes de experiência técnica).

DADOS - Revista de Ciências Sociais, Rio de Janeiro, vol. 60, nº 2, 2017 
Focalizando o mesmo tema, mas discutindo teoricamente elementos das reformas recentes está o texto de Azevedo e Loureiro (2003). Os autores discutem os modelos burocrático-weberiano clássico e gerencialista recente em dimensões como legalidade, impessoalidade, regras formais e universais, sustentando a contínua relevância de elementos do primeiro, como a forma republicana de organização do Estado em regimes democráticos. Perseguindo um conjunto similar de interrogações, Loureiro, Olivieri e Martes (2010) se questionam quanto às consequências das múltiplas superposições entre políticos e burocratas como decisores e implementadores, tendo como referência as políticas econômicas. As autoras sugerem a continuada importância de burocratas e grupos de técnicos com alta formação, em grande parte pelo histórico insulamento das agências econômicas brasileiras.

Uma agenda associada a esta explora as consequências dessas dimensões para a produção de capacidades do/no Estado. Pires e Gomide (2014) analisaram as diferentes combinações em várias políticas recentes entre capacidades políticas e técnico-administrativas na formulação e na implementação recente de iniciativas federais. Perseguindo a mesma agenda, Bichir (2014) analisou como condições institucionais e escolhas políticas levaram à construção de capacidades estatais nos programas de transferência de renda comparativamente no Brasil, na África do Sul e na Argentina.

Cavalcante e Lotta (2015), por outro lado, estudaram os burocratas de médio escalão. Oliveira e Abrucio (2011) também exploraram os perfis de tais burocracias, mas nas áreas de educação e saúde em nível estadual. Esses ocupariam um lugar específico na produção de políticas entre os decisores estratégicos (acima deles) e os supervisores da implementação (abaixo deles). Isso, entretanto, pode variar muito considerando a estrutura das agências e as suas funções formais e efetivas técnico-gerenciais e técnico-políticas (Pires, 2012). Considerando as dificuldades de conceituar tal tipo de burocracias, a maior parte dos estudos adota alguma regra operacional como, por exemplo, considerar apenas certas faixas de DAS, no caso do governo federal.

Um último conjunto de trabalhos explora as consequências das indicações na formação de governo sob o nosso presidencialismo. Como destaca Amorim Neto (1994), a importância dessa questão é óbvia em sistemas parlamentaristas, mas no presidencialismo essa não seria uma dimensão central, considerando apenas as atribuições formais de go- 
verno. Entretanto, como já discutido (Figueiredo e Limongi, 1999), a formação dos gabinetes é central em nosso presidencialismo de coalizão para a construção das maiorias legislativas, criando assimetrias de informação e problemas de delegação de tipo principal-agente para a presidência. Caminhando na mesma direção, Vieira (2013) avaliou de que forma os cargos são usados para coordenação e controle por parte da presidência. Os gabinetes brasileiros são quase sempre de natureza partidária e de coalizão. Isso também se verifica em nível local como mostraram Santos (2001) e Andrade (1998), embora ambos os estudos estivessem focados nas casas legislativas e em suas relações com o Executivo, e não no funcionamento deste último.

Um dos únicos estudos a explorar as coalizões e a formação de governo em âmbito local é Praça e Garcia (2011) sobre os municípios da região metropolitana de São Paulo. Os autores analisaram as relações entre, de um lado, a formação de coalizões de governo e maiorias nos legislativos locais, e, de outro, a composição dos secretariados. A classificação dos secretários por partido e campo ideológico indica a importância das coalizões eleitorais na distribuição de cargos de chefia, mas as secretarias da área social tendem a ficar concentradas no partido do prefeito. Antes deles, diversos artigos contidos em Andrade (1998) e, em especial Couto (1998), analisaram as condições de construção de coalizões entre Executivo e Legislativo no plano local em São Paulo. Garcia (2013), por fim, levantou de forma pioneira a composição dos gabinetes paulistanos entre 1998 e 2012, discutindo o lugar das indicações do secretariado na construção de maiorias na Câmara de Vereadores.

Sumarizando, a produção recente expandiu nosso conhecimento sobre a ocupação de cargos em nível federal, mas sabemos pouco sobre os níveis subnacionais. Além disso, apesar do avanço alcançado com esses estudos, em nenhum caso a mobilidade de cargos foi controlada por indivíduos, apenas pelos tipos de cargos por agência e pelos atributos de seus ocupantes. Dessa forma, pouco se sabe sobre as múltiplas conexões entre agências e governos produzidas pela migração dos indivíduos no tempo. Essas migrações configuram uma rede que costura o tecido relacional do Estado internamente, moldando identidades, fluxos de informação e alianças políticas potenciais, e influenciando a capacidade das agências de produzir políticas públicas. Essa rede pode contribuir para a disseminação da informação e coordenação de ações dentro de governos, de setores de políticas e entre administrações, por

DADOS - Revista de Ciências Sociais, Rio de Janeiro, vol. 60, nº 2, 2017 
afinidade ideológica. A próxima seção explora o tema para o caso do município de São Paulo nos últimos 30 anos.

\section{OS CARGOS EM AGÊNCIAS NO MUNICÍPIO DE SÃO PAULO}

A análise realizada aqui tem como fonte um banco de dados sobre os ocupantes de cargos em instituições públicas do município de São Paulo, criado no Centro de Estudos da Metrópole a partir das informações da base Relação de Nomes e Cargos do Governo do Estado de São Paulo (RNC), organizada pela Fundação Seade ${ }^{2}$. Essas informações indicam quem ocupou um determinado cargo em cada ano ou, inversamente, quais os cargos ocupados por um mesmo indivíduo ao longo do tempo. Essa fonte permite acessar dados sobre a estrutura administrativa dos poderes Executivo (prefeito, vice-prefeito, secretarias, autarquias, fundações e sociedades de economia mista) e Legislativo (apenas o Tribunal de Contas) na esfera municipal, entre 1985 e 2012, exceto os anos de 1988 e 2006, cujas informações foram perdidas na fonte original.

O banco foi montado com os nomes dos ocupantes dos setores de políticas mais importantes (84 secretarias e outros órgãos, principalmente do Executivo $)^{3}$ no primeiro escalão e em mais três níveis hierárquicos abaixo dele - incluindo prefeito, vice-prefeito, secretários e superiores hierárquicos das entidades, chefes de departamentos (e eventualmente divisões setoriais ou regionais - no caso da saúde, educação e cultura, que incluem hospitais, escolas e bibliotecas, por exemplo), bem como as assessorias técnicas, jurídicas e de comunicação dos gabinetes ${ }^{4}$.

A unidade de análise final é o cargo em uma dada agência em certo governo. Para chegar a isso, entretanto, foram adotadas várias decisões metodológicas. Com relação às agências, cada órgão público, autarquia ou empresa pública foi considerado aqui como uma agência, assim como as secretarias (representadas pelo gabinete do secretário). No total, são 34 secretarias, 866 entidades de nível 2, 1.089 de nível 3 e 278 de nível 4 . Neste artigo são analisados apenas indivíduos com cargos pertencentes às entidades de níveis 1 e 2 , o que reduziu o número de indivíduos que ocuparam cargos de 5.037 para 2.027.

Adicionalmente, uma parte dos órgãos públicos mudou de nome, subdividiu-se ou foi extinto ao longo do tempo. Optou-se por padronizar os seus nomes associados à atividade-fim da política ${ }^{5}$, mantendo-se 
sempre o mais recente e adicionando novas secretarias, de acordo com a necessidade. Esse exercício resultou na redução das 84 secretarias originais em 34 por tema de política. Em casos de subdivisão de assuntos de política, classificou-se a agência na secretaria mais afim, ou as duas foram mantidas como duas secretarias separadas a partir de certo governo $^{6}$. O caso mais relevante em termos substantivos dessa decisão metodológica refere-se à Secretaria de Planejamento, que em diferentes governos envolveu apenas planejamento urbano ou planejamento urbano e orçamento. Como discutirei mais adiante, isso tem significado importante para a condução das políticas e para a posição dessa secretaria na rede. De uma forma geral, a estrutura tendeu a se tornar mais complexa ao longo do tempo, tanto pelo aumento do número de agências por governo, quanto pelo aumento da quantidade de cargos por agência ${ }^{7}$.

Um último elemento no tratamento das agências diz respeito a como modelar o tempo, que é sempre uma dimensão difícil de equacionar na análise de redes. No caso deste artigo, o tempo está embutido nos próprios vínculos da rede, visto que é a ocupação de cargos entre duas agências (em dois momentos distintos) por um mesmo indivíduo que especifica uma relação entre agências e/ou governos. Para representar o tempo, portanto, criamos a figura das agências-governo, de modo que se alguém ocupou cargos no gabinete do secretário de Saúde nos governos Maluf e Pitta, por exemplo, é considerado como um vínculo na rede entre dois órgãos (agências-governo) - Saúde-Maluf e SaúdePitta.

O banco de dados construído a partir de tais padronizações foi então processado, de forma a produzir matrizes de filiação com a informação de cargos em agências nas colunas e pessoas nas linhas, para cada um dos oito governos do período. As administrações foram então agrupadas entre si usando o artifício já citado das agências-governo, resultando em uma única matriz de filiação com todas as informações (pessoas em agências-governo). Essa matriz deu origem então a duas outras matrizes de filiação. A primeira matriz inclui governos (com todas as agências colapsadas) como colunas contra pessoas nas linhas, endereçando a pergunta de como a coparticipação em governos os associa entre si. Essa matriz tem sentido muito geral e algo impreciso, pois imputa vínculos entre pessoas apenas por trabalharem em um mesmo governo, mas permite um primeiro olhar sobre proximidades entre governos. A segunda, por outro lado, inclui agências-governo como colu-

DADOS - Revista de Ciências Sociais, Rio de Janeiro, vol. 60, nº 2, 2017 
nas contra pessoas como linhas, endereçando a pergunta quem trabalhou em cada agência, em cada governo. Nesse caso relações entre pessoas são imputadas quando trabalharam em uma mesma agência e um mesmo governo, o que é uma premissa bastante razoável. Por esta razão, a maior parte dos resultados analisados a seguir tem origem nessa segunda matriz. Dada a construção analítica das agênciasgoverno, a rede associa agências e governos em um único retrato intertemporal de conexões.

Apesar da riqueza da informação, há algumas restrições que precisam ser explicitadas. Em primeiro lugar, não temos detalhes sobre o momento da ocupação dos cargos dentro de um governo, não podendo consequentemente eliminar a ocupação de cargos por pequenos períodos. Além disso, não dispomos de informações sobre quem é funcionário de carreira da Prefeitura de São Paulo e quem veio de fora para ocupar cargos. Embora importante, essa informação não está disponível sistematicamente.

Tampouco dispomos de informações biográficas para testar sistematicamente atributos como formação universitária, ocupação de cargos em outros níveis de governo ou filiação partidária. Isso é especialmente problemático com relação à dimensão político-partidária. Embora possamos avançar um pouco na compreensão do fenômeno, há substanciais dificuldades para encontrarmos respostas mais conclusivas aqui por razões de operacionalização da pesquisa, mas também por problemas conceituais. Em primeiro lugar, como é amplamente sabido, as coalizões de governo envolvem inúmeros partidos em configurações mutantes. Em nível local, isso geralmente gera composições do tipo oposição X governo (Andrade, 1998) e, se é politicamente imprescindível fazer parte da coalizão para ocupar cargos importantes, essa dimensão em si se torna muito pouco relevante analiticamente. Ademais, seria impossível determinar a vinculação partidária de quase 2.100 indivíduos, não apenas pelo volume de informações, mas também porque estão aí envolvidas diversas formas de participação partidária e alinhamento ideológico. A filiação partidária é a única dessas vinculações formalizada e mensurável sistematicamente. Esse tipo de informação resolve a análise para cargos eletivos (em que é obrigatória) e em parte para o primeiro escalão (como realizado por Praça e Garcia, 2011 e Garcia, 2013), mas não para os demais cargos. Nesses, confiança partidária se mistura com confiança pessoal das chefias e diversas formas de conhecimento técnico e liderança nas comunidades 
de políticas. Tentamos reduzir o problema explorando informações por governo, campo ideológico e sobre os ocupantes dos cargos mais importantes - secretários e chefes de gabinete.

\section{A REDE DOS GESTORES}

O tema pode ser investigado em duas escalas - no nível agregado de cada administração (testando as associações entre governos por terem pessoas comuns em cargos) e de forma desagregada por agênciasgoverno (analisando como agências e setores de políticas se associam entre si). O primeiro nível sugere dimensões e padrões descritivos gerais, mas que devem ser aprofundados no plano mais desagregado para escaparmos dos problemas criados pela agregação de padrões heterogêneos por agência em unidades ecológicas - os governos. Apesar dos problemas de agregação, entretanto, o primeiro nível já representa uma primeira aproximação aos padrões existentes. Como veremos, alguns desses são comprovados pela análise de maior detalhe, mas outros não. Observemos, portanto, o que nos dizem as evidências neste nível.

\section{Os Governos}

A análise dos governos parte de uma matriz de relações gerada colapsando os contatos de indivíduos que passam por agências, governos por governos. Esse procedimento gera uma matriz quadrada (de conectividade) com 64 casos entre os oito governos do período, agrupados em díades, dois a dois. A Tabela 1 apresenta a informação.

Sob o ponto de vista político, o período analisado é marcado por grande variabilidade nas oito administrações de Mário Covas (PMDB*), Jânio Quadros (PTB), Luiza Erundina (PT), Paulo Maluf (PDS/PPR/PPB), Celso Pitta (PR/PP), Marta Suplicy (PT), José Serra (PSDB) e Gilberto Kassab (DEM). Foram vários os momentos de alternância de grupos políticos controlando o Executivo, sendo que apenas as duplas Paulo Maluf/Celso Pitta e José Serra/Gilberto Kassab representaram clara continuidade política e administrativa entre governos contíguos. Por outro lado, estão representados partidos classificados usualmente pela literatura como de centro (PMDB e PSDB), de esquerda (PT) e de direita (PPR/PPB/PP e DEM).

* Ver lista de siglas dos partidos políticos com os respectivos significados ao final do artigo.

DADOS - Revista de Ciências Sociais, Rio de Janeiro, vol. 60, nº 2, 2017 
Como indicado pela literatura sobre dinâmica eleitoral local, a política municipal em São Paulo passou por dois momentos no período; primeiramente, uma estável oposição entre os partidos de direita e o PT, o final dos anos 1980 até o início dos anos 2000, quando uma oposição PT contra PSDB passou a organizar as disputas locais (Limongi e Mesquita, 2011) ${ }^{8}$. Na Câmara de Vereadores, os partidos vencedores na majoritária (prefeito e vice) quase sempre tiveram a maior bancada (plurality), mas nunca alcançaram maioria absoluta (majority). Isso se mantém, mesmo que consideremos a coligação eleitoral PT/PCdoB/PCB com 43,4\% (Erundina, 32\% só o partido da prefeita), PDS/PL/PTB com $40 \%$ (Maluf, $7,3 \%$ só o partido do prefeito); PPB/PFL com $38,18 \%$ (Pitta, $34,6 \%$ do partido do prefeito); $\mathrm{PT} / \mathrm{PCdoB} / \mathrm{PCB} / \mathrm{PHS}$ com 34,5\% (Marta, 29,1\% do partido da prefeita); PSDB/PFL/PPS com 30,1\% (Serra, com 23,6\% do partido do prefeito) e DEM/PMDB / PRP / PV / PR / PSC com 32,7\% (Kassab, 12,7\% do partido do prefeito) (Garcia, 2013).

Portanto, os prefeitos governaram em todo o período com coalizões partidárias mais amplas do que as suas coligações eleitorais, sendo o secretariado um elemento central na costura das alianças (Couto, 1998). A exceção parcial é representada pelas administrações do $P T$, com proporções de secretários filiados ao partido do prefeito $-72 \%$ e $64 \%$ nos governos Erundina e Marta, respectivamente. O padrão geral, entretanto, foi de composição na formação do gabinete e, como mostrou Garcia (2013), com exceção do governo Erundina (no qual 28\% dos secretários não eram filiados a partidos e $72 \%$ o eram ao PT), os secretariados incorporaram proporções elevadas de indivíduos de partidos distintos ao do prefeito, de $19 \%$ no governo Marta a $53 \%$ no governo Serra ${ }^{9}$.

Entretanto, a análise das coalizões não se confunde com o estudo das conexões internas à rede dos gestores. A Tabela 1 apresenta as conexões entre governos. Lembrando que conexões nesse caso se referem à participação em dois governos de um mesmo indivíduo em cargos de comando. A parte superior da tabela apresenta a informação em números absolutos e a inferior em proporções.

Como podemos ver, há 922 indivíduos comuns a agências em governos. Os números mais expressivos em cada governo se localizam na diagonal, que representa a circulação interna de pessoas dentro de cada governo, de 112 no governo Covas a 541 no governo Kassab. 
A Rede dos Gestores Locais em São Paulo

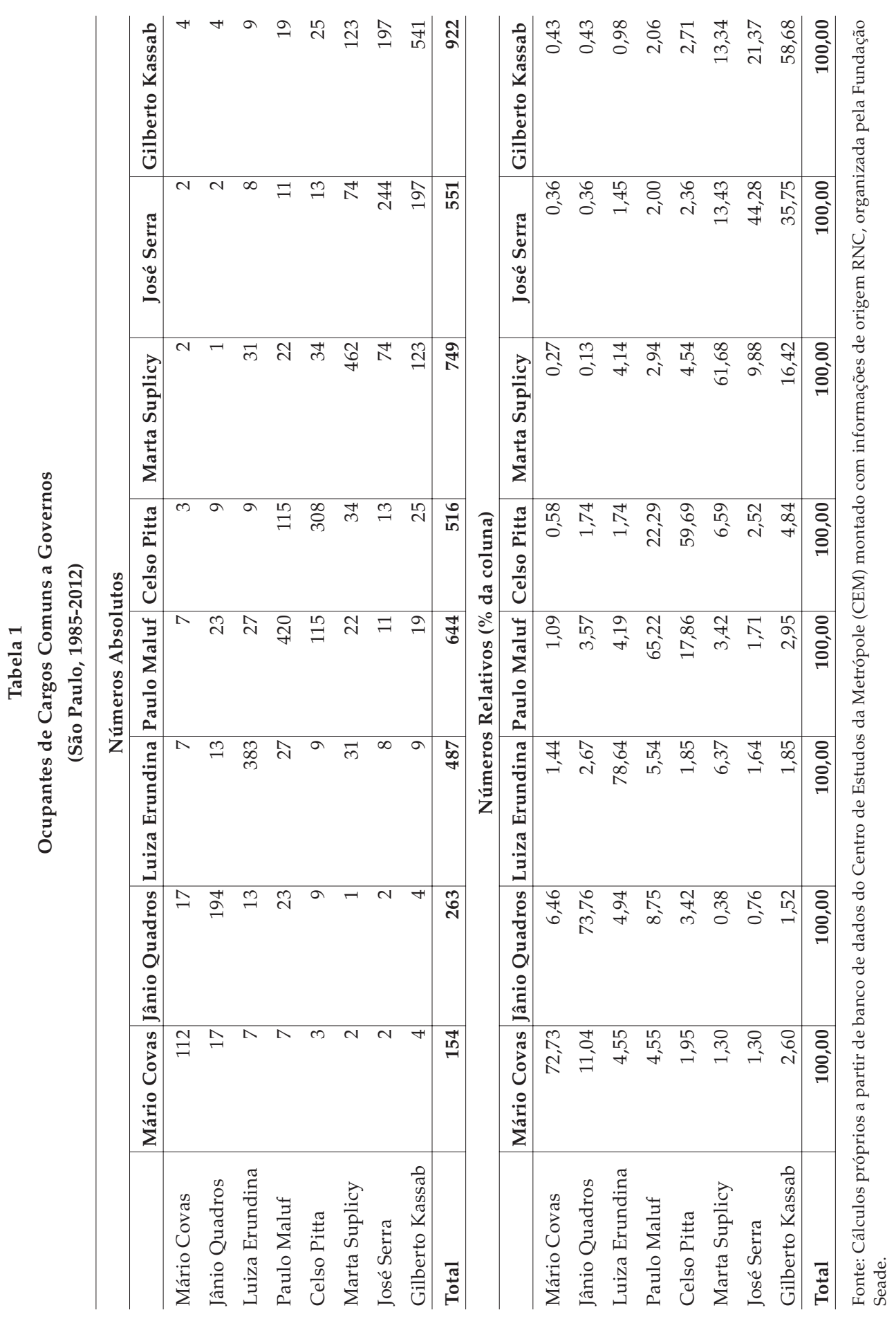


Assim, a maior parte dos ocupantes de cargos comuns é interna a cada governo, um possível indicador do papel da rede na construção de coordenação interna aos governos. Entretanto, se observarmos a diagonal na parte inferior da tabela, vemos que a importância dos vínculos internos foi caindo paulatinamente, sugerindo a construção gradual de uma rede de gestores entre governos.

O total de vínculos de cada governo indica uma segunda dimensão geral - um crescimento temporal quase monotônico dos totais de vínculos - de 154 no governo Covas até 922 no governo Kassab ${ }^{10}$. Isso se deve parcialmente a um efeito metodológico - a informação dos bancos originais foi ficando mais confiável ao longo do tempo. Entretanto, esse aumento expressa também a dinâmica da administração local, que se tornou mais complexa mais recentemente com aumentos significativos nos números de agências, níveis hierárquicos e cargos. De fato, os números de secretarias no banco passaram de 14,16 e 18 nos três primeiros governos para 22, 22 e 30 nos três últimos. Os números totais de cargos nas secretarias em cada governo nos quatro níveis estudados, por outro lado, passou de 470 e 968 nos governos Covas e Jânio, respectivamente, para 4.278 no governo Kassab. Por fim, os tipos de cargos também aumentaram continuamente, passando de 41 no governo para 50 na administração Kassab. Os governos com menor quantidade de cargos diferentes foram os Erundina e Maluf (com 33 e 30 tipos, respectivamente).

Além disso, há outras duas tendências nesse nível de análise. Em primeiro lugar, governos contíguos tendem a ter mais pessoas em comum. Efetivamente, quando se retiram os vínculos internos a cada governo, a média das administrações contíguas é de 68 vínculos, contra apenas 14 dos não contíguos (significativo a 99\%). Esse dado mistura duas dimensões - a manutenção de indivíduos nos cargos em que estavam, mesmo com a troca de gestão (um mero efeito transição), mas também a inércia das próprias políticas em níveis mais técnicos. Não dispomos de informações sobre o tempo de permanência nos cargos, mas esse efeito desaparece quando se examinam as agências separadamente (analisadas na próxima seção).

Em segundo lugar, governos com afinidades político-partidárias tendem a ter mais conexões entre $\mathrm{si}^{11}$. De fato, se desconsiderarmos os vínculos internos a cada governo, a média dos vínculos entre administrações com afinidade (aos blocos de direita, centro e esquerda), é de 59 
ligações, contra apenas 17 em governos sem afinidade ${ }^{12}$. Isso fica ainda mais evidente ao observarmos as proporções na parte inferior da tabela. Entretanto, se desagregarmos a informação pelos três blocos ideológicos, a direita se mostra fortemente significativa (média de 38 contra 23 vínculos dos demais ${ }^{13}$ ), mas o centro e a esquerda não apresentam padrões significativamente diferentes. Portanto, o que podemos afirmar sob o ponto de vista político é que a rede de gestores apresenta coerência para governos de direita, de resto majoritários no período, mas não para governos de centro ou de esquerda. Esses dados corroboram resultados encontrados por Marques (2003) para o caso das políticas de engenharia urbana em São Paulo. Vale destacar a interpenetração do governo Marta com Serra e Kassab, o que pode denotar uma maior estabilidade na estrutura administrativa local em período recente, mas também traços ideológicos menos claros na escolha dos ocupantes de cargos do governo Marta, quando comparado com os do governo Erundina. Esses resultados serão explorados com maior profundidade a seguir.

\section{A REDE DAS AGÊNCIAS-GOVERNO}

Uma primeira interpretação sobre a rede constituída pelas migrações de indivíduos entre cargos poderia focar apenas os ocupantes dos cargos mais importantes das secretarias. Segundo essa hipótese, a rede destacada diria respeito à migração entre governos de indivíduos em posições-chave como secretários e chefes de gabinete, em geral os principais operadores políticos das secretarias. Para analisar essa dimensão, inicio a investigação pela observação dos ocupantes desses cargos, incluindo o levantamento de dados biográficos básicos sobre eles $^{14}$. Os dados indicam uma conectividade relativamente baixa se observamos apenas os ocupantes dos cargos mais importantes, sugerindo que, se a rede realmente é importante, ela é principalmente tecida pelos ocupantes de cargos mais baixos na hierarquia.

O comando das 34 secretarias foi ocupado no período por 220 secretários e 214 chefes de gabinete. $O$ tempo de permanência nesses cargos foi pequeno $-83 \%$ dos indivíduos ficaram como secretários no máximo 2 anos (55\% apenas 1 ano) e 90\% dos chefes de gabinete ocuparam o cargo pelo mesmo período ( $63 \%$ apenas 1 ano), indicando alta rotatividade. Adicionalmente, em seu conjunto, $80 \%$ dos indivíduos ocuparam apenas um cargo.

DADOS - Revista de Ciências Sociais, Rio de Janeiro, vol. 60, n’ 2, 2017 
Quase 30\% (66) dos secretários tiveram outros cargos municipais, aos quais se somam 5 vice-prefeitos que também foram secretários na mesma gestão e 4 prefeitos que foram secretários em outros governos. Apenas 10 indivíduos ocuparam cargos de chefe de gabinete e depois secretários, quase sempre na mesma política e no mesmo governo (com exceção de um único indivíduo entre os governos Serra e Kassab). A quase totalidade dos demais cargos de indivíduos que ocuparam secretarias envolve as mesmas políticas. Nesse sentido, o número de indivíduos ocupando o cargo de secretário em mais de um governo é relativamente alto - 34 (16\% dos secretários), mas é fortemente concentrado em poucos governos com afinidades ideológicas e administrativas - 17 secretários entre os governos Serra e Kassab e 10 entre Maluf e Pitta, sendo os demais 7 secretários completamente dispersos.

Entre os indivíduos incluídos na rede, poucos passaram em algum momento de suas trajetórias por cargos em outros municípios, níveis da federação e o Legislativo. Apenas 5 secretários tiveram cargos em outros municípios, mas 28 secretários tiveram cargos no governo do estado e 16 no governo federal, demonstrando o caráter nacional da ocupação de cargos do primeiro escalão em São Paulo para a construção de carreiras políticas. Isso também é atestado pelo fato de 17 secretários terem sido vereadores, 17 deputados estaduais ( 8 deles também vereadores) e 23 deputados federais (12 deles também estaduais). Quatro secretários foram também vereadores, deputados estaduais e federais em algum momento de suas carreiras. No total, portanto, 45 secretários ocuparam cargos no Legislativo em algum nível (20\% do total de secretários), sendo 36 em outros níveis de governo (16\%). Isso atesta a grande importância política da política local em São Paulo e sugere a existência de importantes conexões políticas produzidas por essas trajetórias para além do Executivo municipal.

Portanto, a migração de secretários e chefes de gabinete produz principalmente conexões externas e conexões entre governos com grande afinidade ideológica, não apresentando grande importância na construção de uma rede interna ao Executivo local. A observação do conjunto dos cargos, entretanto, sugere uma conectividade interna bastante elevada, conformando o tecido relacional do Estado em nível local. A análise mais importante, portanto, diz respeito aos padrões de conexão entre agências, que discrimina os governos, ou o que chamo de agências-governo. A partir da segunda matriz de filiação citada na seção anterior (pessoas em agências-governo), foi gerada uma matriz de 
conectividade ligando agências-governo a agências-governo. Essa rede conecta 158 agências-governos ligadas entre si por terem tido pessoas em comum ocupando cargos, formando quase 25 mil conexões potenciais. O Sociograma 1 apresenta a rede, com os tamanhos dos nós representando centralidades de grau ponderadas. Essa rede apresenta grau médio de 5,9 vínculos, densidade de 0,038 , índice de centralização de $8,4 \%$, diâmetro de apenas 11 passos e distância média de apenas $3,4^{15}$. Apesar da baixa densidade, portanto, a rede apresenta conectividade e atividades bastante razoáveis.

\section{Sociograma 1}

Rede das Agências-governos Conectadas por Indivíduos, PMSP, 1985-2012

(Tamanhos dos nós definem centralidades de grau ponderadas) ${ }^{16}$

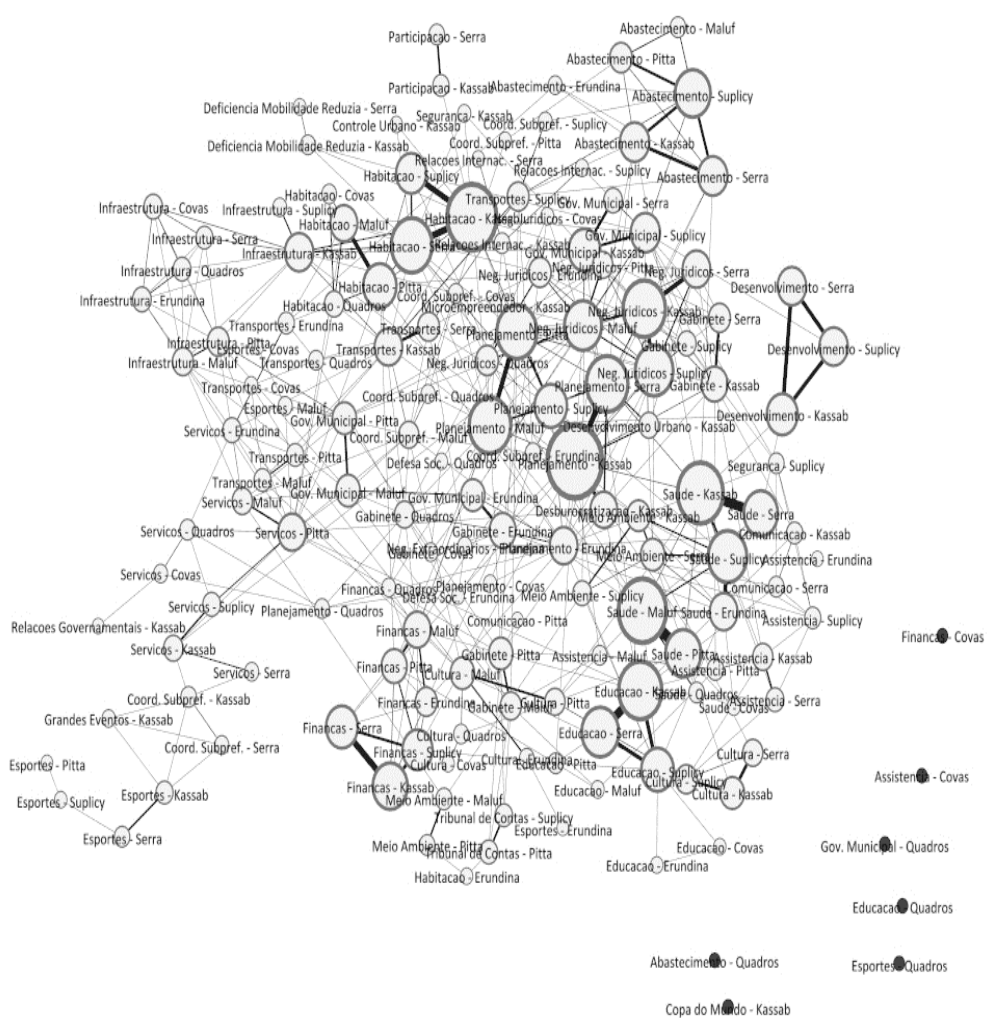

Fonte: Cálculos próprios a partir de banco de dados do CEM e informações da RNC, Fundação Seade.

Como se pode ver, a rede apresenta grande complexidade. O que a estrutura e como suas regiões se organizam - por governos, por setores

DADOS - Revista de Ciências Sociais, Rio de Janeiro, vol. 60, n² 2, 2017 
de política, por grande área de política? Algumas pistas já aparecem na observação da figura. Em primeiro lugar, há agrupamentos e relações internos a setores de políticas entre governos, como entre abastecimento acima à direita, esportes à esquerda abaixo, transportes e infraestrutura acima à esquerda e educação, assistência, cultura e saúde abaixo à direita. A região central da rede parece estar mais associada a secretarias de gestão, planejamento e governo. Por outro lado, secretarias de engenharia urbana e sociais parecem se localizar mais nas periferias da rede, as primeiras acima à esquerda e as segundas abaixo à direita. Uma vista geral do sociograma também sugere que as gestões em si não são a única agregação dos vínculos (internamente a cada governo), tampouco as afinidades ideológicas, pois a tendência maior de conexão se dá entre agências de uma mesma área de políticas ou mesmo política pública.

De fato, a figura confirma a existência de vários princípios que estruturam a rede simultaneamente, superpondo padrões de especialização temática, trânsito de gestores internamente a cada governo e entre eles ${ }^{17}$. Esses padrões apontam para a importância de duas dimensões distintas: 1) especialização temática/formação de campos de políticas públicas e 2) afinidade político-partidária e ideológica entre governos. As duas dimensões produzem potencialmente coordenação, mas de natureza técnica/temática no primeiro caso e de apoio político no segundo. Essas observações preliminares, entretanto, devem ser exploradas em maior profundidade.

Para começar a investigar a dimensão temática e de especialização, podemos analisar medidas básicas de centralidade de secretarias e setores de políticas de forma univariada. As secretarias mais centrais dentre as 34 estudadas, na média dos oito governos em termos de grau (degree) são, em ordem decrescente: Planejamento, Negócios Jurídicos, Gabinete do Prefeito, Habitação, Secretaria de Governo, Infraestrutura, Serviços e Finanças. Os destaques negativos entre as políticas mais importantes são Saúde (12aa), Educação (15ํ) e Assistência (16aㅡ). A lista da medida de intermediação (betweeness) pouco altera esta observação: Planejamento, Serviços, Secretaria de Governo, Habitação, Negócios Jurídicos, Gabinete do prefeito, Subprefeituras (novidade), Saúde e Transportes e Cultura (outra novidade).

A primeira conclusão, portanto, é que as secretarias da área social têm em geral baixa centralidade na rede dos gestores locais, e as agências mais centrais são ligadas à articulação política, gestão, finanças e polí- 
ticas urbanas. É importante aqui comentar e destacar a Secretaria de Planejamento. Como já descrito, em alguns governos essa secretaria foi responsável pelos planejamentos urbano e orçamentário (sendo a Secretaria de Finanças responsável pela arrecadação e pelo gasto), enquanto em outros governos o orçamento foi deslocado para esta última, que passa a controlar todas as atividades ligadas a recursos. Nas primeiras análises desses dados, considerei que a fusão desses assuntos representava um problema metodológico, mas com o amadurecimento da análise passei a acreditar que o papel da Secretaria de Planejamento fazia sentido substantivamente em termos dos conteúdos das políticas públicas (representando um achado de pesquisa em si) e ajudava a explicar a centralidade e a intermediação dessa agência na rede $^{18}$. Essas duas atividades - planejamento do uso e da ocupação do solo e planejamento da distribuição de recursos orçamentários - são ambas politicamente conflitivas, fortemente redistributivas e centrais para a construção da coalizão de apoio dos prefeitos, assim como para a sua operação cotidiana. Por essa razão, a Secretaria de Planejamento ocupa posições na estrutura da rede mais parecidas com as das secretarias de articulação política e gestão do que das urbanas e sociais.

A construção da intersetorialidade e a formação de capacidades de gestão, já destacada por estudos monográficos recentes (Requena, 2015; Campos, 2016; Ralize, 2015), talvez explique o caráter menos nítido dos resultados a partir do governo Marta Suplicy. Essa interpretação é reforçada pela maior centralidade das áreas-meio, fundamentais politicamente, sobretudo gestão, finanças, planejamento e articulação política. Segundo a hipótese de Praça e Garcia (2011), as secretarias da área social deveriam ser ocupadas por indivíduos próximos ao prefeito e seu partido. Nesse caso, se esperariam maiores densidades entre as secretarias dessas áreas entre gestões com afinidades ideológicas, o que os dados aqui analisados não comprovam. Parece-me mais razoável considerar como hipótese que prefeitos tendem a querer controlar os cargos ligados a suas políticas prioritárias. Em consequência, a premissa dos autores faria sentido apenas em gestões que centram sua agenda na área social. Alternativamente, podemos argumentar que a menor centralidade das áreas sociais é causada pela concentração dos seus gestores em indivíduos mais técnicos e especialistas, que tenderiam a permanecer internamente em cada setor.

Podemos explorar essas dimensões de forma mais aprofundada classificando as agências em cinco grandes campos e observando-os em detalhes: Articulação política; Gestão/Finanças; Urbanas; Políticas

DADOS - Revista de Ciências Sociais, Rio de Janeiro, vol. 60, n’ 2, 2017 
sociais e Outras ${ }^{19}$. Os resultados basicamente se repetem, e, em média, os tipos mais centrais, considerando tanto grau como intermediação, são Engenharia/urbano, Articulação política e Gestão/Finanças.

A interpretação anterior sobre profissionalização é reforçada pelas densidades internas e pelas redes egocentradas por setores de política. Os dados indicam uma enorme diferença entre os valores absolutos das densidades internas a cada tipo de políticas - 1,58 entre agênciasgoverno de Articulação, 1,29 internamente a Gestão, 0,48 a Urbanas e 0,62 a Sociais -, mas baixas densidades entre os tipos de políticas ${ }^{20}$. As redes egocentradas das agências-governo também apresentam, em média, muito mais conexões internas a cada tipo de política do que entre elas ${ }^{21}$. Entre os tipos, se destaca a relação entre articulação e gestão, reforçando a ideia de construção de coordenação no conjunto da prefeitura. Esses tipos de políticas são ao mesmo tempo conectados internamente e imbricados entre $\mathrm{si}^{22}$.

Portanto, as áreas mais centrais são ocupadas por secretarias de articulação e gestão e finanças, seguidas das de políticas urbanas (que incluem planejamento), ficando as da área social na periferia. Também sabemos que a maior parte dos vínculos ocorre dentro de tipos de políticas e de blocos de afinidade ideológica, em especial da direita e da esquerda. Mas, qual é exatamente a estrutura do conjunto da rede? Podemos explorar a estrutura analisando as sub-redes por tipo de política. Trata-se de um artifício analítico, visto que toda a rede está conectada entre si, mas podemos selecionar os nós de forma a que apareçam apenas aqueles que correspondem a certas áreas temáticas, uma a uma. $\mathrm{O}$ Sociograma 2 apresenta a parcela da rede envolvendo apenas as agências da área social.

Como se pode ver, há uma intensa conexão entre agências de saúde, educação, assistência e cultura, sendo as agências das duas primeiras áreas as de maior centralidade (expressa no tamanho dos nós, no sociograma). Algumas agências de esportes se conectam entre si à esquerda e em outro agrupamento, acima. Mas com a exceção do governo Erundina, se encontram isoladas do restante da área social ${ }^{23}$.

A conectividade interna da área de políticas urbanas é ainda maior, como podemos ver no Sociograma $3^{24}$. Destaca-se o agrupamento das agências de Infraestrutura, estudadas por mim em detalhes em Marques (2003). Também aparecem fortemente interconectadas agências de Habitação acima, de Planejamento ao centro e de Transportes 


$$
\text { Esportes- Covas }
$$
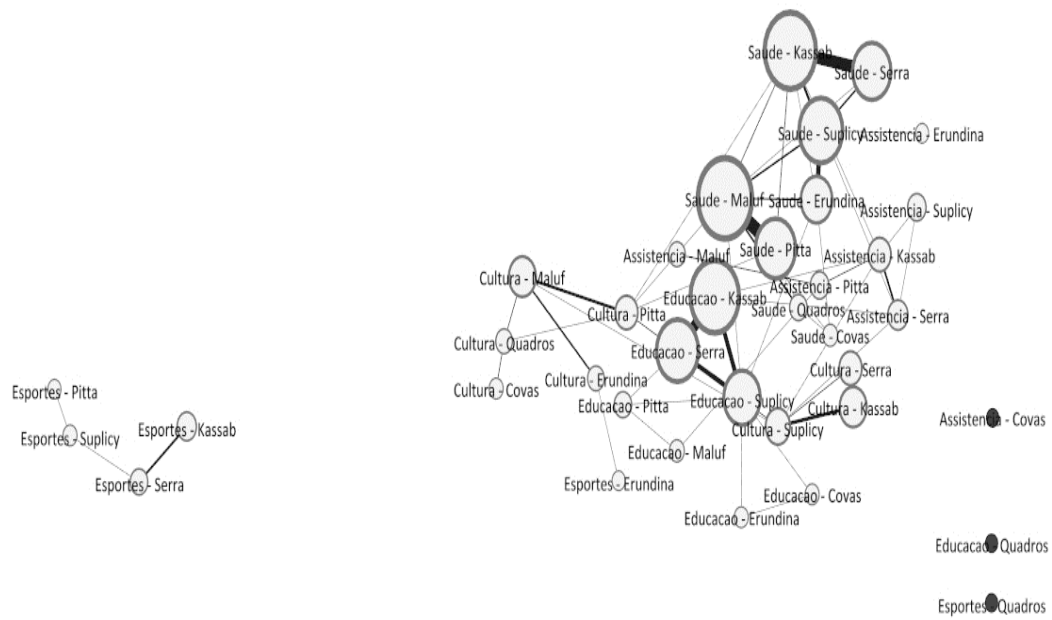

Fonte: Cálculos próprios a partir de banco de dados do CEM e informações da RNC, Fundação Seade.

ao centro e à esquerda. Serviços e Subprefeituras têm localização e posições mais periféricas acima e abaixo.

O Sociograma 4, por fim, apresenta as conexões entre as agências de articulação política e de gestão. As duas áreas temáticas são apresentadas juntas, pois os dados relacionais formam um único tecido contí nuo ${ }^{25}$. As agências de Finanças e Negócios Jurídicos formam dois agrupamentos muito densos internamente, mas sem conexões entre si. Quem os conecta são os gabinetes dos prefeitos e as secretarias de governo de quase todos os prefeitos (com exceção de Marta Suplicy, Serra e Pitta, que se localizam diretamente dentro do agrupamento dos $\mathrm{Ne}-$ gócios Jurídicos). Como esses são os três últimos governos analisados, essa posição relativa diferente talvez denote uma mudança no padrão geral de conexões da articulação de governo. Os gabinetes de Maluf e Pitta integram ainda o Tribunal de Contas do Município (TCM) abaixo.

Portanto, os dados indicam agrupamentos muito densos por tema de política, reforçando a tese da especialização, principalmente internos a

DADOS - Revista de Ciências Sociais, Rio de Janeiro, vol. 60, nº 2, 2017 


\section{Sociograma 3}

Agências da Área Urbana, PMSP, 1985-2012

(Tamanhos dos nós definem centralidades de grau ponderadas)

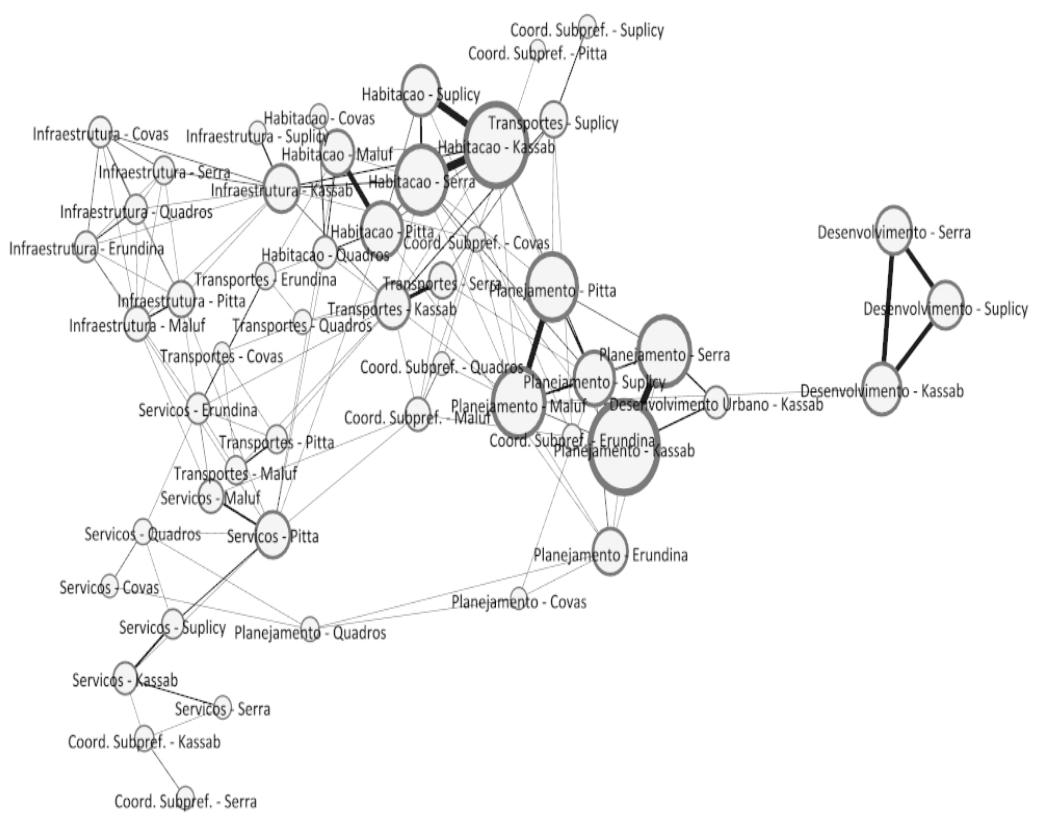

Habitaca@Erundina

Fonte: Cálculos próprios a partir de banco de dados do CEM e informações da RNC, Fundação Seade.

finanças, negócios jurídicos e infraestrutura, e, em um patamar mais baixo, Saúde, Transportes e Habitação/Planejamento e Educação/Assistência. Entre estas, merecem destaque as posições de Planejamento e Habitação, mediando as conexões no interior das agências urbanas, e os Gabinetes e Secretarias de governo, conectando a área de gestão internamente. Ademais, as agências-governo de articulação e gestão em geral e as de Planejamento em especial conectam áreas temáticas entre si. As outras secretarias participam de forma periférica da estrutura, embora em um ou outro governo possam estabelecer pontes entre áreas. Além disso, está confirmada a menor centralidade da área social, mas também a especialização temática como uma dimensão geral de construção de vínculos na rede.

Um último elemento da estrutura merece destaque. A existência de conexões que cruzam setores e governos é principalmente concentrada 
Agências de Articulação Política e de Gestão, PMSP, 1985-2012

(Tamanhos dos nós definem centralidades de grau ponderadas)

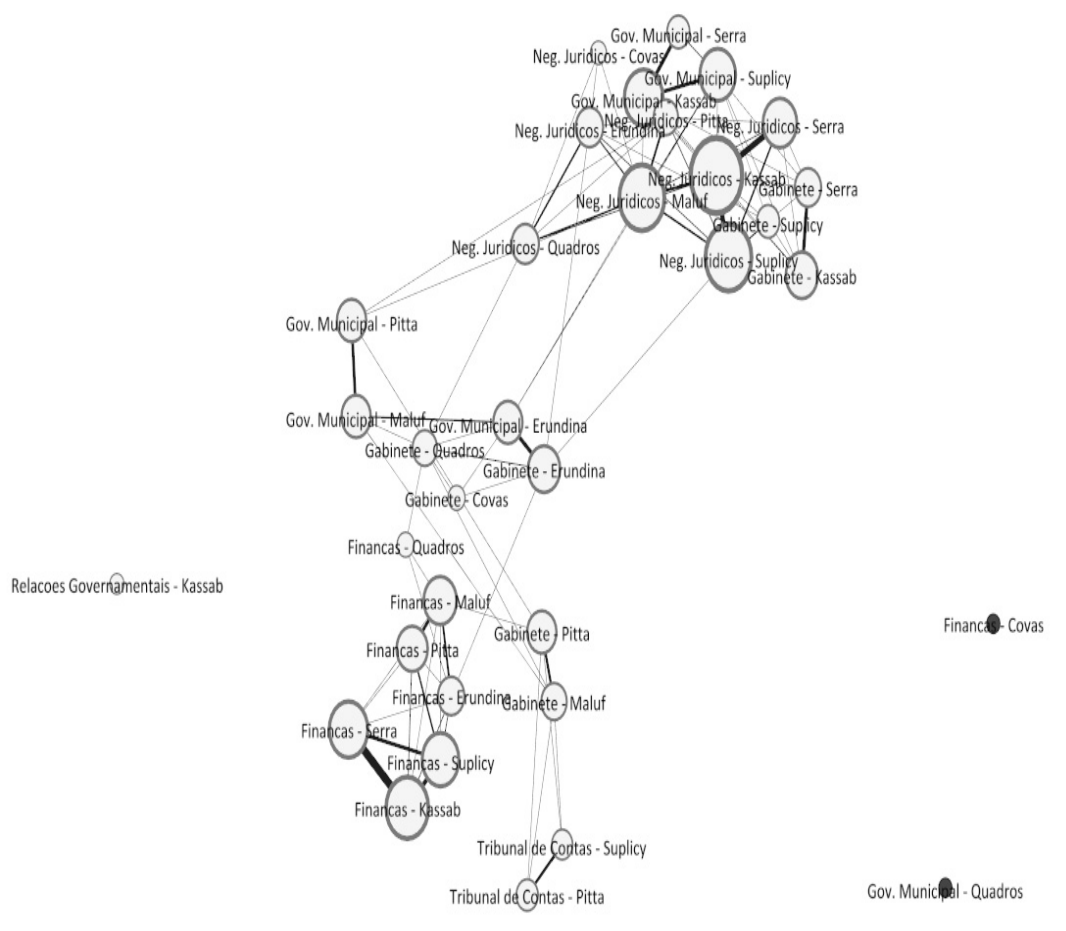

Fonte: Cálculos próprios a partir de banco de dados do CEM e informações da RNC, Fundação Seade.

em vínculos de baixa frequência. Se selecionarmos no sociograma da rede completa (Sociograma 1 ) apenas as relações com frequências mais altas (2 ou mais vínculos), obtemos uma figura muito mais simples e que desconecta muitas das agências-governo. Aparecem como isolados principalmente subcomponentes por tema ou política ${ }^{26}$. Tanto vínculos fortes quanto fracos são importantes, mas os primeiros marcam conexões mais densas e estáveis ligadas a apoio político e cooperação, enquanto os segundos usualmente veiculam e disseminam informações e auxiliam na coordenação de atividades. O Sociograma 5 apresenta a informação por agências-governos e os isolados retirados da figura, para melhor visualização.

Como se pode ver, os componentes periféricos e isolados conectam na maior parte das vezes agências-governo de mesma política em

DADOS - Revista de Ciências Sociais, Rio de Janeiro, vol. 60, n’ 2, 2017 
Eduardo Cesar Leão Marques

Sociograma 5

Rede das Agências-governos Conectadas apenas por Dois Vínculos ou mais PMSP, 1985-2012

(Tamanhos dos nós definem centralidades de grau ponderadas)

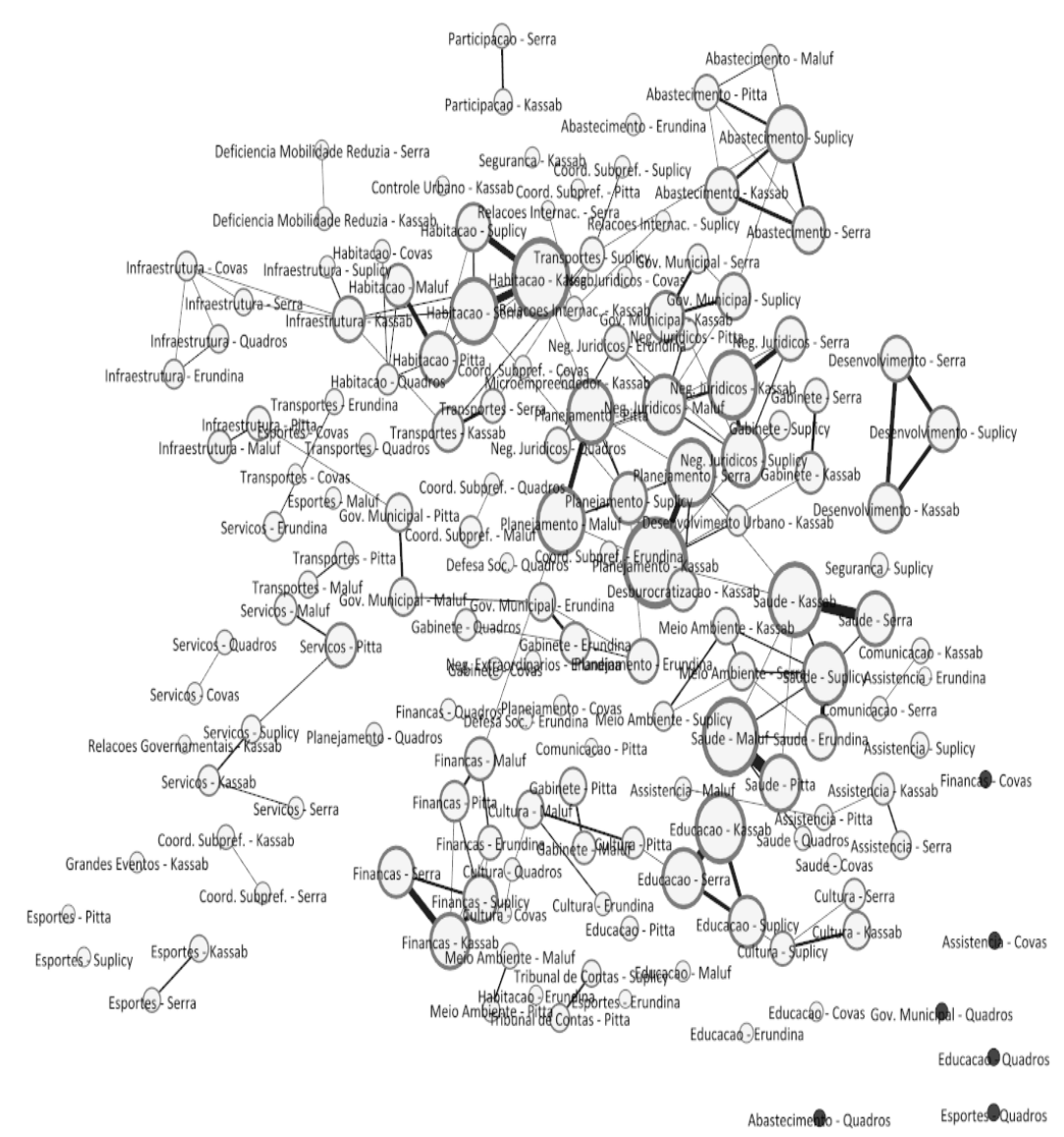

Fonte: Cálculos próprios a partir de banco de dados do CEM e informações da RNC, Fundação Seade.

governos afins, em especial Maluf-Pitta e Serra-Kassab (à direita e acima e à esquerda e abaixo). Há também alguns componentes de maior tamanho por política, como cultura, assistência, serviços, relações internacionais, educação e desenvolvimento, principalmente (à direita e abaixo). O mais importante, entretanto, é o componente central. No centro desse componente estão agências-governo de Planejamento, articulando as áreas mais densas do componente organizadas por política, com agrupamentos de Negócios Jurídicos (à esquerda), Saúde (abaixo), Finanças (à direita), Governo e Gabinete (à direita), 
Habitação (acima) e, através dessa última, Transportes e Serviços. Portanto, embora algumas agências da área social sejam conectadas ao conjunto da rede por vínculos fracos (Educação, Cultura e Esportes, além de Assistência, que se isola de forma atomizada e nem aparece nos componentes da Figura), a Saúde permanece no componente principal. No centro da rede de relações mais densas dos gestores estão agências de Planejamento em vários governos, mas agências de Negócios Jurídicos, Governo, Habitação, Transportes, Abastecimento e Infraestrutura em alguns governos também são importantes na estrutura, estabelecendo pontes com suas áreas temáticas. Uma parte importante dessas pontes é estabelecida por agências dos governos Suplicy (Governo, Planejamento, Negócios Jurídicos, Abastecimento e Transportes), Serra (Planejamento e Habitação) e Kassab (Planejamento, Habitação, Infraestrutura e Transportes). Assim como nos sociogramas anteriores, não parece haver especial predominância de certas agências-governo em certas administrações ou campos ideológicos. Portanto, apesar de complexa e interconectada, a rede é composta por um núcleo mais central de agências de gestão e urbanas, ligadas por elos fortes ao qual se vinculam os campos de política e agências mais periféricas através de ligações fracas.

Por fim, outra entrada de análise importante diz respeito ao lugar da dimensão político-partidária/ideológica na ocupação dos cargos, que se conecta com os temas centrais da formação de governo e da construção de maiorias legislativas. Os dados de centralidade medidos pelo grau e pela intermediação (betweeness) indicam que os governos com agências mais centrais (em médias, em ordem decrescente) foram Maluf, Jânio e Kassab, seguidos de Marta Suplicy e Luiza Erundina em um patamar mais baixo. Como consequência lógica, o campo ideológico com maior centralidade da rede é a direita, seguido da esquerda. $\mathrm{O}$ maior número de governos de direita e a centralidade desse campo no controle da política local em São Paulo (Marques, 2003) ajudam a explicar o resultado (ao mesmo tempo que são por ele parcialmente explicados). Isso é produto, é claro, das preferências eleitorais locais, que geraram uma hegemonia eleitoral da direita por muito tempo (Limongi e Mesquita, 2011), mas também diz respeito à conformação dos campos de política mais centrais, como a engenharia urbana, fortemente hegemonizada pela direita (Marques, 2003). Mais recentemente essa hegemonia tem se transformado com o crescimento eleitoral do centro em substituição à direita (Limongi e Mesquita, 2011) e com uma maior estruturação de burocracias, como já indicado.

DADOS - Revista de Ciências Sociais, Rio de Janeiro, vol. 60, nº 2, 2017 
Em termos de agências-governos, os resultados anteriores se combinam. As agências mais centrais em termos de grau são (também em ordem decrescente): Planejamento-Maluf; Planejamento-Kassab; Planejamento-Pitta; Planejamento-Erundina; Negócios Jurídicos-Maluf; Serviços-Pitta, Secretaria de Governo-Marta; Habitação-Pitta; Secretaria de Governo-Kassab; Negócios Jurídicos-Kassab.

Por outro lado, os dados de densidade indicam de fato a existência de conexões mais intensas entre agências de governos com maior afinidade ideológica. As maiores densidades são como seria de se esperar entre cada campo, em ordem decrescente - esquerda/esquerda $(0,657)$; direita / direita $(0,504)$ e centro/ centro $(0,353)$. Entre governos, por outro lado, as maiores densidades seguem os contatos da Tabela 1 , sendo mais altas realmente entre os governos Maluf e Pitta $(0,41)$; Serra e $\operatorname{Kassab}(0,35)$; Marta e Kassab $(0,20)$ e Marta e Serra $(0,16)$. Esse padrão confirma a importância dos governos de continuidade administrativa, independentemente do partido (nos dois primeiros casos), mas também indica a maior conectividade das últimas gestões entre si, como já destacado. De outro modo, quando são consideradas apenas relações entre agências governo com dois ou mais vínculos (dois ou mais gestores em comum), as densidades entre governos e entre blocos de afinidade caem dramaticamente ${ }^{27}$, indicando que governos e blocos tendem a ser conectados por poucos vínculos, em um padrão que pode ser caracterizado de vínculos fracos.

Vale acrescentar um elemento não explorado aqui pela ausência de dados sistemáticos - certos partidos políticos constroem estratégias para "fidelizar" áreas de política, de forma a aproveitar os rendimentos crescentes da especialização e das relações políticas com atores associados a elas (movimentos sociais, sindicatos, empresas etc.). São exemplos dessa prática na última década, o PC do B na área de esportes, o PTB na área de trabalho e o PP na área de habitação, apenas para citar alguns. Esse parece ser um elemento importante na construção dos gabinetes, mas que não pode ser explorado na análise da rede por falta de dados sobre participação partidária.

\section{CONCLUSÕES}

A análise mostrou que a migração dos indivíduos entre cargos efetivamente costura um tecido relacional denso e complexo na administração municipal em São Paulo. Portanto, existe uma rede de burocratas 
de alto escalão em nível local que associa gestões de matizes ideológicos e setores de políticas distintos, produzindo efeitos em várias escalas distintas, associadas a dimensões políticas/ideológicas e técnicas/de especialização. Se a migração dos ocupantes dos cargos mais importantes permite antecipar conectividade com outras escalas de governo e do Legislativo, mas não internamente ao Executivo de forma densa, a rede formada pela migração do conjunto dos ocupantes de cargos costura um tecido relacional do Estado em nível local. Em termos políticos, a rede conecta entre si governos com afinidades político-partidárias, em especial governos do campo ideológico da direita. Governos de esquerda e de centro também são ligados entre si, mas também são ligados aos demais, sem um claro padrão.

Por outro lado, a rede articula internamente cada governo, contribuindo potencialmente para a construção de coordenação entre órgãos e reforçando a especialização temática em vários casos. Além disso, ela associa setores e áreas de políticas públicas entre governos, tecendo uma dimensão importante dos padrões relacionais do Estado em nível local. Em termos temáticos, as agências de gestão e articulação política se encontram em posições mais centrais da rede, e as agências da área social na periferia. Se considerarmos apenas os vínculos fortes, entretanto, a rede tende a ficar muito menos densa, embora ainda conformando regiões distintas por políticas, com as agências de Planejamento operando a conexão entre agrupamentos densos internamente e escassamente conectados entre si. A análise do impacto potencial desses padrões para a produção e implementação de políticas depende da realização de estudos que cruzem tais padrões com as dinâmicas das políticas como Marques (2003), ainda escassos entre nós.

(Recebido para publicação em abril de 2016) (Aprovado para publicação em abril de 2017)

DADOS - Revista de Ciências Sociais, Rio de Janeiro, vol. 60, n’ 2, 2017 
Eduardo Cesar Leão Marques

\section{NOTAS}

1. Esse número é variável por governo, já que cargos e agências deixam de existir e outros são criados. O número total, na verdade, é de 84 secretarias, mas que se reduzem a 34 ao compatibilizarmos denominações, recomposições e subdivisões ao longo do tempo. A segunda seção discute o assunto em detalhes.

2. Os dados entre 1985 e 1994 foram acessados em relatórios em papel, mas entre 1995 e 2006 foram consultados relatórios em formato magnético (1995 a 2001 em disquetes e 2002 a 2006 em CD-ROM). A partir de 2007, os dados foram consultados diretamente no site da Fundação Seade. Os anos de 1988 e 2006 não puderam ser encontrados.

3. Foram elas: gabinete, governo, finanças, assuntos jurídicos, orçamento, transportes, educação, saúde, habitação, assistência, infraestrutura e obras, subprefeituras, serviços, verde, cultura, esportes, desenvolvimento urbano, abastecimento, controle urbano, trabalho, defesa, segurança, comunicação, relações internacionais, negócios extraordinários, parcerias, modernização, deficiência, Copa do Mundo, grandes eventos, relações governamentais e incentivo ao microempreendedor.

4. É importante esclarecer que cada um desses três níveis corresponde a posições no organograma das agências hierarquicamente organizadas (variando, portanto, entre políticas), e não a níveis de cargos diretamente. Todos os cargos no gabinete de uma secretaria, por exemplo, são considerados como situados no nível 1, mesmo que alguns deles sejam superiores a outros - secretário, chefe de assessoria técnica e assistente jurídico, por exemplo. O nível 2 pode dizer respeito a uma escala hierárquica mais baixa nessa mesma secretaria - uma superintendência, por exemplo, mas também ao gabinete do presidente ou diretor de um órgão subordinado à secretaria, como a Superintendência de Habitação Popular no interior da Secretaria Municipal de Habitação. Não há, portanto, qualquer relação entre esses níveis e os conceitos de burocracia de alto, médio e baixo escalão discutidos na literatura recente de políticas públicas.

5. Nesse sentido, os setores perderam a sua especificidade e, por exemplo, a "Divisão de Depósito de Materiais Inservíveis" virou divisão, assim como o “Departamento de Sistemas A" virou departamento.

6. São frequentes as renomeações, subdivisões e fusões de órgãos. Aárea de assistência, por exemplo, ficou a cargo no período das Secretarias: Municipal da Família e Bem-Estar Social, Municipal do Bem-Estar Social, Municipal de Assistência e Desenvolvimento Social. Obras públicas foram produzidas pelas Secretarias: Municipal de Vias Públicas, de Vias Públicas, Municipal de Infraestrutura Urbana e Municipal de Serviços e Obras. Os órgãos foram renomeados e fundidos no banco, tentando ao máximo manter e seguir os objetos de política pública.

7. Os 111 cargos também foram padronizados, mas não são analisados neste artigo.

8. A mesma dinâmica se verificou também nos 29 municípios da região metropolitana de São Paulo. Entre 1985 e 2008, o partido com mais prefeitos eleitos foi o PSDB (44), seguido do PT (37), do PTB (31), do PMDB (29), do PFL (26) e do PL (14). Mas entre 1985 e 2000 (4 eleições), o PSDB ganhou apenas 13 mandatos, enquanto entre 2000 e 2008 (3 eleições), venceu 31 pleitos. A tendência do PT também foi crescente, passando de 9 para 28 prefeitos, enquanto o PTB, o PMDB, o PFL e o PL decaíram (20 e 11; 23 e 6; 19 e 7 e 8 e 6, respectivamente). Isso é parcialmente explicado pela criação do 
PSDB a partir do PMDB em 1988, mas expressa também a substituição da direita pelo centro e a ascensão do PT desde 1988. Esses dados foram retirados do site da Fundação Seade.

9. Entre 1989 e 2012, pertenceram a outros partidos $25 \%$ dos secretários no governo Maluf (sendo 50\% sem partidos e 25\% do partido do prefeito); $23 \%$ no governo Pitta (sendo $71 \%$ sem partidos e $6 \%$ do partido do prefeito); $19 \%$ no governo Marta (sendo $17 \%$ sem partidos e $64 \%$ do partido do prefeito); $53 \%$ no governo Serra (sendo $39 \%$ sem partidos e $8 \%$ do partido do prefeito); $35 \%$ no governo Kassab (sendo $28 \%$ sem partidos e 37\% do partido do prefeito). Esses dados são oriundos de Garcia (2013).

10. De fato, a correlação entre uma variável ordinal referente a governo e os vínculos (sem considerar os vínculos internos) é de 0,33 (significativa a 99\%).

11. Considerando que o governo do DEM representou continuidade administrativa com o do PSDB (Gilberto Kassab era o vice de José Serra, pertencendo ao PFL quando se elegeu. Em 2007 o PFL se transformou em Democratas, e em 2008 o então viceprefeito se elegeu por este último partido), classificamos essa administração como de centro. A sua classificação como de direita, entretanto, não produziria mudanças nos resultados.

12. Diferença significativa a $99 \%$.

13. Novamente significativa a $99 \%$.

14. É preciso dizer que a confiabilidade dessas informações é menor do que a relativa à ocupação de cargos. Como inexiste uma fonte oficial centralizada para os dados biográficos, as informações a seguir têm como origem pesquisa na internet com os nomes dos secretários e ocupantes de cargos.

15. Grau (degree) diz respeito à quantidade de vínculos que um nó tem com outros nós. A densidade é a proporção dos vínculos realmente existentes divididos pelos teoricamente possíveis. Índice de centralização compara a centralização da rede em torno dos nós mais centrais com uma rede totalmente centralizada (como uma estrela em que todos os vínculos saem do centro). O diâmetro é a menor distância da rede, dentre os seus maiores caminhos. A distância média, por fim, é a média das distâncias de todos os caminhos na rede.

16. O sociograma foi gerado no software Gephi, utilizando as rotinas "Fruchterman Reingold" e depois Force Atlas 2 (www.gephi.org). Os demais sociogramas apresentam partes selecionadas desse, conservando as posições dos nós.

17. Essa hipótese é também apoiada preliminarmente pelas redes egocentradas. Uma rede egocentrada representa um subconjunto da rede total, mas considerando apenas os contatos diretos de um dado nó de referência (chamado ego) e seus vínculos entre si. As redes egocentradas das agências-governo incluem, em média, mais contatos internos aos setores de política e aos campos ideológicos, mas menor proporção de vínculos internos a governos. Isso quer dizer que os vínculos tecem uma rede que articula ao mesmo tempo setores de política internamente e governos entre si.

18. Vale dizer que no amadurecimento desse argumento muito me ajudaram conversas com as colegas Renata Bichir e Úrsula Peres, ambas da Escola de Artes, Ciências e Humanidades, da Universidade de São Paulo (EACH-USP).

19. São elas: Articulação política: gabinete, governo, relações governamentais; Gestão/Finanças: finanças, negócios jurídicos, orçamento, TCM; Urbanas: transportes, habitação, infraestrutura e obras, subprefeituras, serviços, desenvolvimento urba-

DADOS - Revista de Ciências Sociais, Rio de Janeiro, vol. 60, nº 2, 2017 


\section{Eduardo Cesar Leão Marques}

no, controle urbano; Sociais: educação, saúde, assistência, cultura, esportes; Outras: verde, abastecimento, trabalho, defesa, segurança, comunicação, relações internacionais, negócios extraordinários, parcerias, modernização, deficiência, Copa do Mundo, grandes eventos, e incentivo ao microempreendedor.

20. Em todos os casos foram calculadas densidades por grupo incluindo os valores da diagonal, pois nos interessa considerar também as relações internas aos órgãos nos cálculos. Por essa razão, as densidades não variam apenas entre 0 e 1 .

21. O indicador E-I médio das egocentradas para tipo de política é de -0,303, comparável e inverso ao entre governos de 0,328 , indicando que as redes ego tecem internamente os tipos de políticas ao mesmo tempo que conectam governos entre si.

22. Reforça essa interpretação ainda a existência de 28 agrupamentos de vínculos fortes, todos envolvendo agências-governo de secretarias iguais em governos distintos, nas mais variadas áreas.

23. Uma informação parecida pode ser obtida com as redes egocentradas das agênciasgoverno de um tipo de política, nesse caso, sociais. Na área social (39 agências), o conjunto das egocentradas inclui 67 agências, resultando em uma média de 1,7 agências por agência "ego" desse tipo de política.

24. Neste caso, as egocentradas conectam 110 agências a partir das 51 agências de temas urbanos, resultando em uma taxa de 2,2. As egocentradas destacam ainda as secretarias de planejamento conectando a área urbana à de articulação/gestão (sobretudo finanças, o que é esperado pois programação orçamentária esteve incluída no planejamento em certos momentos).

25. As egocentradas de articulação e gestão são as que articulam maiores quantidades de agências, em média, confirmando o seu papel central de estruturação da rede. São alcançadas 82 agências a partir das 34 originais, resultando em uma taxa de 2,4.

26. Componentes são tramos desconectados da rede.

27. Os valores mais altos, entretanto, continuam se localizando nos governos internamente, na esquerda internamente e nos mesmos pares de governos. 
A Rede dos Gestores Locais em São Paulo

\section{REFERÊNCIAS BIBLIOGRÁFICAS}

ABRANCHES, Sérgio. (1988), "Presidencialismo de Coalizão: O Dilema Institucional Brasileiro". DADOS - Revista de Ciências Sociais, vol. 31, no 1, pp. 5-34.

ABRUCIO, Fernando. (2007), “Trajetória Recente da Gestão Pública Brasileira: Um Balanço Crítico e a Renovação da Agenda de Reformas". Revista de Administração Pública, vol. 41, número especial, pp. 67-86.

; LOUREIRO, Maria Rita; ROSA, Carlos. (1998), “Radiografia da Alta Burocracia Federal Brasileira: O Caso do Ministério da Fazenda". Revista do Serviço Público, vol. 49, no 4, pp. 47-82.

ABRUCIO, Fernando; PEDROTI, Paula; PÓ, Marcos. (2010), "A Formação da Burocracia Brasileira: A Trajetória e o Significado das Reformas Administrativas”, in M. R. Loureiro; F. Abrucio; R. Pacheco (orgs.), Burocracia e Política no Brasil: Desafios para o Estado Democrático Brasileiro. Rio de Janeiro, Ed. FGV.

AMORIM NETO, Octavio. (1994), “Formação de Gabinetes Presidenciais no Brasil: Coalizão versus Cooptação". Nova Economia, vol. 4, no 1, pp. 9-34.

ANDRADE, Regis. (1998), Processo de Governo no Município e no Estado. Uma Análise a partir de São Paulo. São Paulo, Edusp.

AZEVEDO, Clovis; LOUREIRO, Maria Rita. (2003), "Carreiras Públicas em uma Ordem Democrática: Entre os Modelos Burocrático e Gerencial". Revista do Serviço Público, vol. 54, no 1, pp. 45-61.

BICHIR, Renata. (2014), “Capacidades Estatais para a Implementação de Programas de Transferência de Renda: Os Casos de Brasil, Argentina e África do Sul”. Textos para Discussão, no 2032, Ipea.

BRESSER-PEREIRA, Luiz Carlos. (2007), “Burocracia Pública e Classes Dirigentes no Brasil”. Revista de Sociologia e Política, no 28, pp. 9-30.

CAMPOS, Marcos. (2016), Ferramentas de Governo: Instrumentação e Governança Urbana nos Serviços de Ônibus em São Paulo. Dissertação (Mestrado em Ciência Política). Universidade de São Paulo, São Paulo.

CAVAlCANTE, Pedro; LOTTA, Gabriela. (2015), "Perfis, Trajetórias e Relações: Em Busca de uma Análise Abrangente dos Burocratas de Médio Escalão do Governo Federal", in P. Cavalcante; G. Lotta (orgs.), Burocracia de Médio Escalão: Perfil, Trajetória e Atuação. Brasília, Enap, pp. 293-308

COUTO, Cláudio. (1998), “Negociação, Decisão e Governo: Padrões Interativos na Relação Executivo-Legislativo e o Caso Paulistano", in R. Andrade (org.), Processo de Governo no Município e no Estado. Uma Análise a partir de São Paulo. São Paulo, Edusp.

CRUZ, Rachel. (2009), Carreiras Burocráticas e Meritocracia. Trabalho apresentado no II Congresso Consad de Gestão Pública. Brasília, 6-8 de maio.

D’ARAÚJO, Celina; LAMEIRÃO, Camila. (2011), “Dirigentes Públicos Federais de Alto Escalão no Governo Lula", in J. C. Cardoso Júnior (org.), Burocracia e Ocupação no Se tor Público Brasileiro. Rio de Janeiro, Ipea.

DADOS - Revista de Ciências Sociais, Rio de Janeiro, vol. 60, nº 2, 2017 


\section{Eduardo Cesar Leão Marques}

FIGUEIREDO, Argelina; LIMONGI, Fernando. (1999), Executivo e Legislativo na Nova Ordem Constitucional. Rio de Janeiro, FGV Ed.

GARCIA, Joice. (2013), Executivo e Legislativo no Âmbito Municipal: A Formação de Gabinetes no Município de São Paulo (1989-2012). Dissertação (Mestrado em Administração Pública), Fundação Getulio Vargas, São Paulo.

GOMES, Angela. (1994), “Novas Elites Burocráticas”, in A. C. Gomes et al. (orgs.), Engenheiros e Economistas: Novas Elites Burocráticas. Rio de Janeiro, FGV Ed.

GOUVÊA, Gilda. (1994), Burocracia e Elites Burocráticas no Brasil. São Paulo, Paulicéia.

GUEDES, André. (2013), Elites Estatais e Reforma do Estado na Nova República: O Projeto ENAP e a Formação da Carreira de Gestor Governamental no Brasil. Tese (Doutorado em Sociologia), Universidade de Brasília, Distrito Federal.

LAZZARINI, Sérgio. (2011), Capitalismo de Laços. São Paulo, Campus.

LIMONGI, Fernando; MESQUITA, Lara. (2011), “Estratégia Partidária e Clivagens Eleitorais: As Eleições Municipais Pós-redemocratização", in L. Kowarick; E. Marques (orgs.), São Paulo: Novos Percursos e Atores. São Paulo, Editora 34/CEM.

LOPEZ, Felix (org.). (2015), Cargos de Confiança no Presidencialismo de Coalizão Brasileiro. Brasília, Ipea, pp. 107-138.

LOPEZ, Felix; PRAÇA, Sérgio. (2015), “Critérios e Lógicas de Nomeação para o Alto Escalão da Burocracia Federal Brasileira", in F. Lopez (org.), Cargos de Confiança no Presidencialismo de Coalizão Brasileiro. Brasília, Ipea.

LOUREIRO, Maria Rita; ABRUCIO, Fernando. (1999), "Política e Burocracia no Presidencialismo Brasileiro". Revista Brasileira de Ciências Sociais, vol. 14, no 41, pp. 69-89.

LOUREIRO, Maria Rita; OLIVIERI, Cecília; MARTES, Ana Cristina. (2010), “Burocratas, Partidos e Grupos de Interesse: O Debate sobre Política e Burocracia no Brasil”, in M. R. Loureiro; F. Abrucio; R. Pacheco (orgs.), Burocracia e Política: Desafios para o Estado Democrático no Século XXI. Rio de Janeiro, Ed. FGV.

MACHADO, Rosangela. (2013), Burocracia e Política no Brasil: Análise da Inserção da Carreira dos Especialistas em Políticas Públicas e Gestão Governamental na Máquina Pública. Tese (Doutorado em Ciências Sociais), Unicamp, Campinas, São Paulo.

MARQUES, Eduardo. (2003), Redes sociais, Instituições e Atores Políticos no Governo da Cidade de São Paulo. São Paulo, Annablume/Fapesp.

MINTZ, Beth; SCHWARTZ, Michael. (1981), "Interlocking Directorates and Interest Group Formation". American Sociological Review, vol. 46, no 6, pp. 851-869.

MONTEIRO, Lorena. (2013), “Reforma da Administração Pública e Carreiras de Estado: O Caso dos Especialistas em Políticas Públicas e Gestão Governamental no Poder Executivo Federal". Revista de Administração Pública, vol. 47, no 5, pp. 1117-1143.

NUNES, Edson. (1997), A Gramática Política do Brasil: Clientelismo e Insulamento Burocrático. Rio de Janeiro, Jorge Zahar/Enap.

OLIVEIRA, Vanessa; ABRUCIO, Fernando. (2011), Entre a Política e a Burocracia: A Importância dos Burocratas de Nível Médio para a Produção de Políticas Públicas em Saúde e Educação. Trabalho apresentado no 35 Encontro Anual da Anpocs, 24-28 de outubro, Caxambu. 
OLIVIERI, Cecília. (2007), "Política, Burocracia e Redes Sociais: As Nomeações para o Alto Escalão do Banco Central do Brasil". Revista de Sociologia e Política, no 29, pp. 147-168.

PIRES, Roberto. (2012), "Burocracias, Gerentes e suas Histórias de Implementação", in C. A. Faria (org.), Implementação de Políticas Públicas: Teoria e Prática. Belo Horizonte, Editora PUC-Minas, pp.182-220.

; GOMIDE, Alexandre. (2014), "Burocracia, Democracia e Políticas Públicas: Arranjos Institucionais de Políticas de Desenvolvimento". Textos para Discussão, no 140, Ipea.

PRAÇA, Sérgio; GARCIA, Joice. (2011), Formação de Governo no Nível Municipal: O Caso dos Municípios Paulistas. Trabalho apresentado no 35o Encontro Anual da Anpocs, 24-28 de outubro, Caxambu.

PRAÇA, Sérgio; FREITAS, Andréa; HOEPERS, Bruno. (2012), “A Rotatividade dos Servidores de Confiança no Governo Federal Brasileiro, 2010-2011". Novos Estudos CEBRAP, no 94, pp. 91-107.

RALIZE, Samuel. (2015), Muito Além da Lata de Lixo: A Construção da Política Pública e a Organização do Mercado de Limpeza Urbana no Município de São Paulo. Dissertação (Mestrado em Ciência Política). Universidade de São Paulo, São Paulo.

REQUENA, Carolina. (2015), O Paradigma da Fluidez do Automóvel: Burocracias Estatais e Mobilidade em São Paulo. Dissertação (Mestrado em Ciência Política). Universidade de São Paulo, São Paulo.

SANTOS, Fabiano. (2001), O Poder Legislativo nos Estados: Diversidade e Convergência. Rio de Janeiro, FGV Ed.

VIEIRA, Marcelo. (2013), Controle Político da Burocracia no Presidencialismo de Coalizão. Tese (Doutorado em Ciência Política), IESP/UERJ, Rio de Janeiro. 


\section{Eduardo Cesar Leão Marques}

\section{Lista de Siglas dos Partidos Políticos}

DEM - Democratas

PCB - Partido Comunista Brasileiro

PCdoB - Partido Comunista do Brasil

PDS - Partido Democrático Social

PFL - Partido da Frente Liberal

PHS - Partido Humanista da Solidariedade

PL - Partido Liberal

PMDB - Partido do Movimento Democrático Brasileiro

PP - Partido Progressista

PPB - Partido Progressista Brasileiro

PPR - Partido Progressista Reformador

PPS - Partido Popular Socialista

PR - Partido da República

PRP - Partido Republicano Progressista

PSC - Partido Social Cristão

PSDB - Partido da Social Democracia Brasileira

PT - Partido dos Trabalhadores

PTB - Partido Trabalhista Brasileiro

PV - Partido Verde 
A Rede dos Gestores Locais em São Paulo

RESUMO

A Rede dos Gestores Locais em São Paulo

Este artigo investiga um tema quase completamente inexplorado da formação de governo e da construção de burocracias e capacidades em âmbito local no Brasil: a existência de uma rede de decisores e burocratas de alto nível que se deslocam entre posições de comando de diferentes agências no governo de uma grande cidade. Redes desse tipo costuram agências, áreas de política pública e administrações e são responsáveis por uma parte substancial das práticas e processos informais que constroem governança por detrás dos procedimentos administrativos formais. Partindo de um banco de dados inédito, o artigo analisa a rede construída pela migração de decisores entre departamentos e agências da prefeitura de São Paulo entre 1985 e 2012, envolvendo dezenas de secretarias e aproximadamente cinco mil indivíduos em mais de uma centena de diferentes posições administrativas. Os resultados indicam a existência de um denso e complexo tecido relacional que conecta o interior de cada governo, costura áreas temáticas internamente entre agências e governos e liga governos com afinidades políticas. Os dados indicam que a estrutura da rede é um resultado ao mesmo tempo de processos de especialização temática e de clivagens políticas, criando importantes elementos de coordenação entre agências e governos.

Palavras-chave: políticas públicas; posições institucionais; coordenação de políticas; redes sociais; São Paulo

\section{ABSTRACT \\ The Network of Local Administrators in São Paulo}

This paper investigates an almost completely unexplored facet of government formation and of the construction of bureaucracies and capabilities at the local level: the existence of a network of decision makers and senior bureaucrats who move over time between positions at different agencies in the administration of a big city. Networks of this kind weave agencies, policy areas and administrations together and are responsible for a substantial part of the informal practices and processes that construct governance and underlie formal governmental procedures. Setting out from a newly constructed database, the article analyses the network built by the migration of top officials between departments and agencies in São Paulo city from 1985 to 2012, involving dozens of secretaries and approximately five thousand individuals in more than one hundred different government positions. The results indicate the existence of a dense and complex relational fabric that connects the interior of each government, weaves thematic areas internally between agencies and governments, and links governments with the same political affinities. The data indicates that the network structure is an outcome of processes associated simultaneously with political cleavages and policy field specialization, providing important elements for coordination between agencies and administrations.

Keywords: public policies; institutional positions; policy coordination; social networks; São Paulo

DADOS - Revista de Ciências Sociais, Rio de Janeiro, vol. 60, n² 2, 2017 
Eduardo Cesar Leão Marques

\section{RÉSUMÉ \\ Le Réseau des Administrateurs Locaux à São Paulo}

Cet article s'intéresse à une facette encore assez peu étudiée de la formation des gouvernements et de la construction de bureaucraties et de capacités locales au Brésil: l'existence d'un réseau de décideurs et de bureaucrates de haut niveau qui naviguent entre différents postes de direction au sein de divers organismes liés au gouvernement d'une grande ville. Ces réseaux pénètrent organismes, secteurs politiques et administrations publiques et sont responsables d'une partie substantielle des pratiques et processus informels qui construisent la gouvernance en arrière-plan des procédures administratives formelles. En nous fondant sur une base de données inédite, cet article analyse le réseau construit par la migration des décideurs entre différents départements et autres agences de la Mairie de São Paulo entre 1985 et 2012, qui a impliqué des dizaines de départements et environ 5.000 personnes occupant plus d'une centaine de positions administratives différentes. Les résultats indiquent l'existence d'un tissu relationnel dense et complexe qui occupe le cœur des gouvernements, conforme des domaines thématiques partagés entre organismes et gouvernements, et lient ces derniers en fonction des affinités politiques. Les données indiquent que la structure du réseau est le résultat simultané de processus de spécialisation thématique et de clivages politiques permettant de créer d'importants éléments de coordination entre agences et gouvernements.

Mots-clés: politiques publiques; postes institutionnels; coordination de politiques; réseaux sociaux; São Paulo

\section{RESUMEN}

\section{La Red de Gestores Locales en São Paulo}

Este artículo investiga un tema casi completamente inexplorado de la formación de gobiernos y de la construcción de burocracias y capacidades en el ámbito local en Brasil: la existencia de una red de decisores y burócratas de alto nivel que transitan entre posiciones de mando de diferentes agencias en el gobierno de una gran ciudad. Las redes de este tipo anexan agencias, áreas de política pública y administraciones, y son las responsables de una parte sustancial de las prácticas y procesos informales que construyen gobernanza por detrás de los procedimientos administrativos formales. Partiendo de un banco de datos inédito, el artículo analiza la red construida por la migración de decisores entre departamentos y agencias del ayuntamiento de São Paulo entre 1985 y 2012, que incluía a decenas de secretarias y a aproximadamente cinco mil personas en más de un centenar de cargos administrativos diferentes. Los resultados indican la existencia de un denso y complejo tejido relacional que conecta el interior de cada gobierno, vincula áreas temáticas internamente entre agencias y gobiernos, y asocia gobiernos con afinidades políticas. Los datos apuntan que la estructura de la red es el resultado de procesos de especialización temática y, al mismo tiempo, de fracturas políticas, creando importantes elementos de coordinación entre agencias y gobiernos.

Palabras clave: políticas públicas; posiciones institucionales; coordinación de políticas; redes sociales; São Paulo 